\title{
3D-printing techniques in a medical setting: a systematic literature review
}

\author{
Philip Tack ${ }^{1 *}\left(\mathbb{D}\right.$, Jan Victor ${ }^{2}$, Paul Gemmel ${ }^{3}$ and Lieven Annemans ${ }^{1}$
}

\author{
*Correspondence: \\ Philip.Tack@Ugent.be \\ ${ }^{1}$ Department of Public \\ Health, Ghent University, De \\ Pintelaan 185, 9000 Ghent, \\ Belgium \\ Full list of author information \\ is available at the end of the \\ article
}

\begin{abstract}
Background: Three-dimensional (3D) printing has numerous applications and has gained much interest in the medical world. The constantly improving quality of 3D-printing applications has contributed to their increased use on patients. This paper summarizes the literature on surgical 3D-printing applications used on patients, with a focus on reported clinical and economic outcomes.
\end{abstract}

Methods: Three major literature databases were screened for case series (more than three cases described in the same study) and trials of surgical applications of 3D printing in humans.

Results: 227 surgical papers were analyzed and summarized using an evidence table. The papers described the use of 3D printing for surgical guides, anatomical models, and custom implants. 3D printing is used in multiple surgical domains, such as orthopedics, maxillofacial surgery, cranial surgery, and spinal surgery. In general, the advantages of 3D-printed parts are said to include reduced surgical time, improved medical outcome, and decreased radiation exposure. The costs of printing and additional scans generally increase the overall cost of the procedure.

Conclusion: 3D printing is well integrated in surgical practice and research. Applications vary from anatomical models mainly intended for surgical planning to surgical guides and implants. Our research suggests that there are several advantages to 3D-printed applications, but that further research is needed to determine whether the increased intervention costs can be balanced with the observable advantages of this new technology. There is a need for a formal cost-effectiveness analysis.

Keywords: 3D printing, Additive manufacturing, Innovation, Surgery, Review, Patient specific, Customized, Anatomic model

\section{Background}

3D printing has become more important in recent decades. 3D printing allows threedimensional renderings to be realized as physical objects with the use of a printer. It has revolutionized prototyping and found applications in many nonmedical fields. In medicine, the technology has applications in orthopedics, spinal surgery, maxillofacial surgery, neurosurgery, and cardiac surgery, amongst various other disciplines.

Doctors mostly work with two-dimensional X-ray images or two-dimensional images obtained from computed tomography (CT) or magnetic resonance (MR) scans to gain insight into pathologies. This requires excellent visualization skills from the surgeon. The 
recent emergence of three-dimensional renderings of $\mathrm{CT}, \mathrm{MR}$, plain radiography, and echo imagery has improved visualization of complex pathologies but lacks tactile qualities. 3D-printed objects can be used to study complex cases, to practice procedures, and to teach students and patients. [1].

Furthermore, some current surgical procedures are complex and require guidance to avoid damaging essential parts of the body, or to obtain an acceptable esthetic outcome [2]. In some cases, this guidance requires substantial amounts of ionizing radiation and can heavily increase surgical time [3]. Additionally, anatomical defects can require custom prosthetics to repair damage as accurately as possible [4].

The need for improved visualization and surgical outcomes has given rise to 3D-printed anatomical models, patient-specific guides, and 3D-printed prosthetics. The growing surgical applications of 3D printing have made it interesting to analyze the current implementation of this new technology.

This article gives an overview of the current usage of 3D-printing techniques in human medicine, more specifically surgery, based on a systematic literature review using three major literature databases.

We attempted to identify domains and usages where the technology is fairly common or has been used several times, and to report its potential advantages and disadvantages. As healthcare budgets are under pressure and both hospitals and doctors desire to improve efficiency, we have included cost and cost effectiveness as variables in the analysis.

This resulted in the following research questions: (1) which surgical 3D-printing applications are commonly reported in human medicine? (2) What advantages, disadvantages, and cost consequences do surgical 3D-printing applications have compared to the standard of care?

\section{Methods}

A systematic literature review was conducted using the Web of Science, PubMed, and Embase.

The search strategy was kept broad to ensure no relevant papers were excluded. The search headings were '3D printing,' 'three dimensional printing', 'additive manufacturing,' and 'rapid prototyping. After expert consultation, an additional search was performed to include 3D-printing applications referred to as 'patient specific' guides and implants. Relevant articles found in references were added as well.

The initial database search was conducted in February 2015. An additional search was conducted in December 2015, to include all papers published in 2015. Only full papers of controlled trials and case series of minimum four cases, written in English, where 3D printing is applied for surgical purposes on living humans, were considered.

Manual screening of the titles and abstracts was performed so as to include only papers consistent with the application of 3D-printing techniques to human medical ends. The inclusion criteria were the use of 'computer aided manufacturing' (CAM), 'computer aided design' (CAD), 'additive manufacturing' (AM), 'printed scaffold,stereolithography', and 'reverse engineering' for human medicine. Additionally, titles containing 'customized,' 'patient specific', 'templates' and 'physical model' were retained in order not to overlook potential uses. 
Examples of virtual 3D modeling or rendering without physical 3D models were excluded. Only clinical uses were considered; cadaveric, in vitro, and animal studies were not retained.

Only case series with more than three cases and clinical trials were selected, because we associate these with higher integration of the technology in the medical field. Publications written in languages other than English, or with no full paper available, were excluded based on the abstract.

Papers retained after the full-text review were analyzed in detail using an evidence table to report relevant study characteristics and outcomes. Based on commonly reported outcomes in the literature, we included the following variables: impact on operation room (OR) time or treatment time, level of accuracy of the printed part, impact on exposure to radiation, clinical outcome, cost, and cost effectiveness.

The impact on OR time/treatment time refers to time savings in the operation room or for the treatment itself, compared to the conventional procedure. This does not include savings in rehabilitation, nor does it take account of any additional work done by the surgeon prior to surgery.

The accuracy of the printed part was used to assess the quality of the printed part. For anatomical models, the resemblance to the original form was taken into account. For guides and implants, the accuracy of the printed part was assessed based on intraoperative adaptations and the need to abort the intended procedure in favor of the conventional procedure. The occurrence of few changes to the guide or few procedures being converted to the conventional procedure was considered to reflect good accuracy.

Radiation exposure was captured when mentioned explicitly by authors. Clinical outcome was assessed as improved surgical precision or improved final outcome. Note that there is an overlap between accuracy of the printed part and clinical outcome, as accurate guides result in better postsurgical alignment and therefore a positive outcome score. Cost was captured when mentioned by the authors. As some authors have begun to debate cost effectiveness, we considered this variable when it was mentioned.

\section{Results}

After the initial database search in February 2015, 7482 papers were selected. The additional search in December 2015, including all 2015 publications, resulted in 1114 papers. 3386 duplicates were removed. Screening of titles resulted in 1873 retained articles, with 2223 articles being excluded.

353 papers were selected for full reading; 1520 articles were excluded, most of which were case studies.

After reading the full papers, 224 papers were retained for further analysis. With the exception of three papers, all were surgical. Nonsurgical papers were excluded. Six relevant papers found in references of the accepted papers were added to the final analysis table, bringing the total number of papers to 227.

An overview of the selected papers ranked by medical domain is given in Additional file 1. One paper was split in three, as three different studies were published together. Another paper was split in two since two different studies were discussed in it. This resulted in 230 observations in the 227 included papers.

The search strategy and reasons for exclusion are given in Fig. 1. 


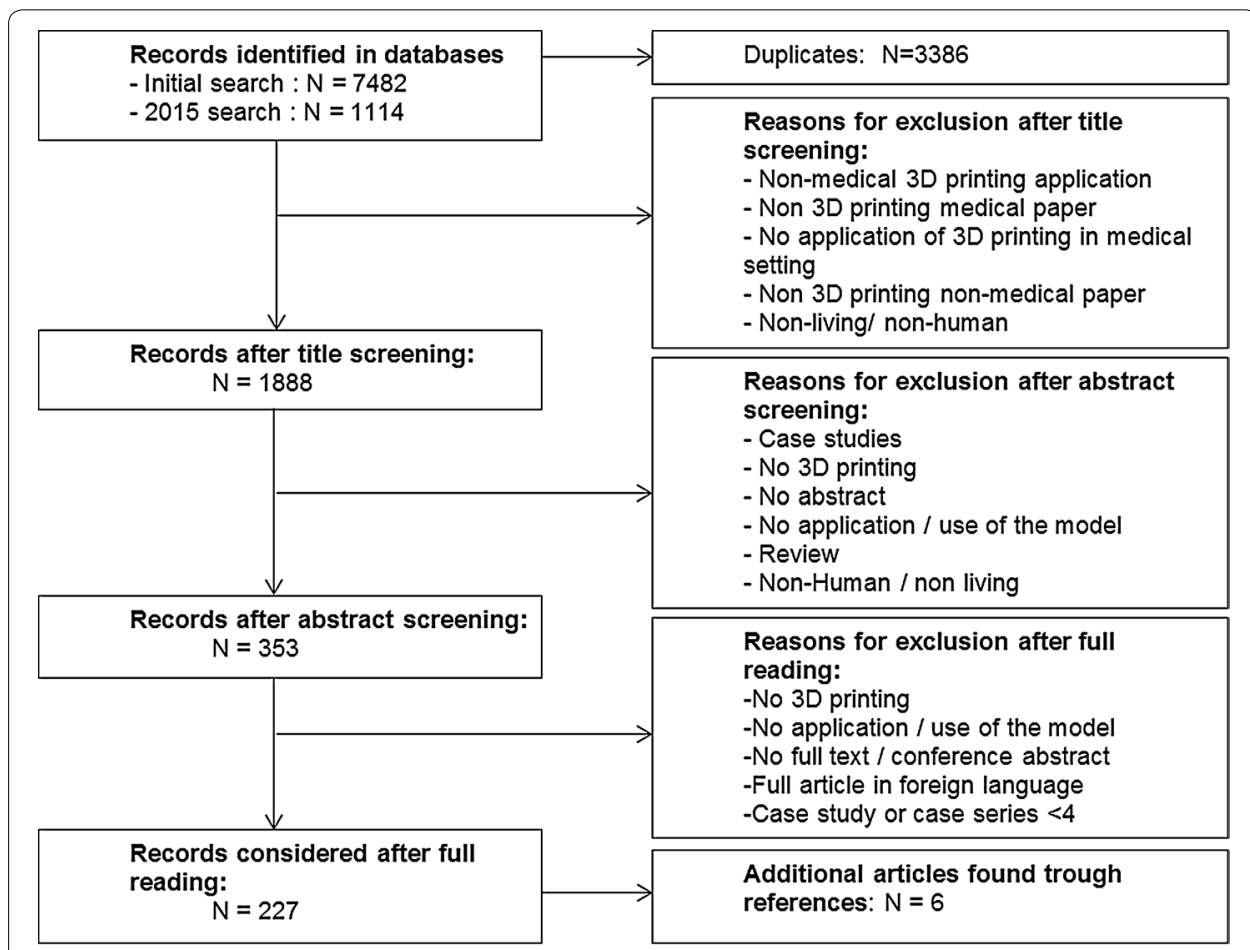

Fig. 1 Search strategy and reasons for exclusion

Only two papers were dated before 2000. Eight papers were dated between 2000 and 2005, 30 between 2006 and 2010, and 189 between January 2011 and 25 February 2015. Figure 2 gives an overview of the number of selected papers per year.

The published results on 3D printing most often concern surgical guides $(60 \%)$ and models for surgical planning (38.70 \%) (Fig. 3). Additionally, there are reports on the outcomes of using 3D printing to make custom implants (12.17\%), molds for prosthetics (3.91\%), models of implant shaping (1.74\%), and models for patient selection (0.87\%). Note that some papers used 3D-printing techniques for multiple purposes, resulting in a total greater than $100 \%$.

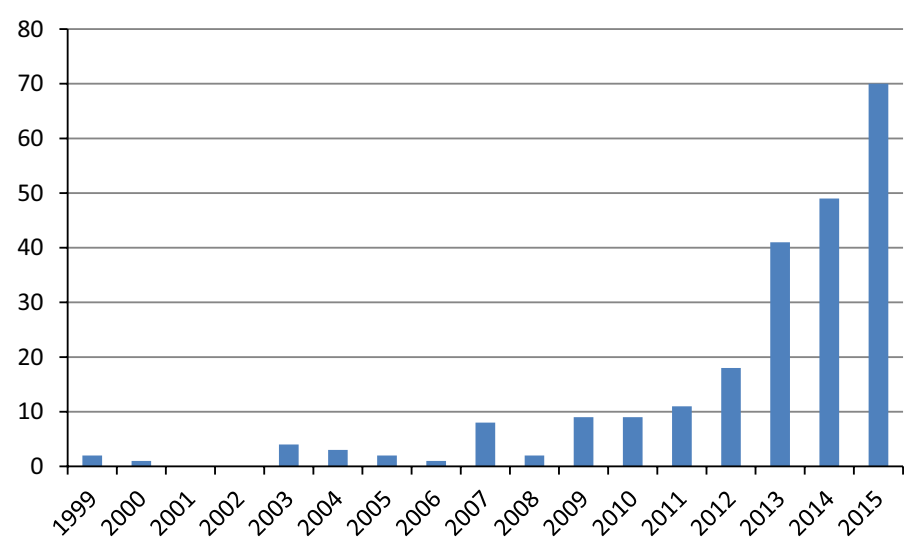

Fig. 2 Overview of selected papers based on publication year 


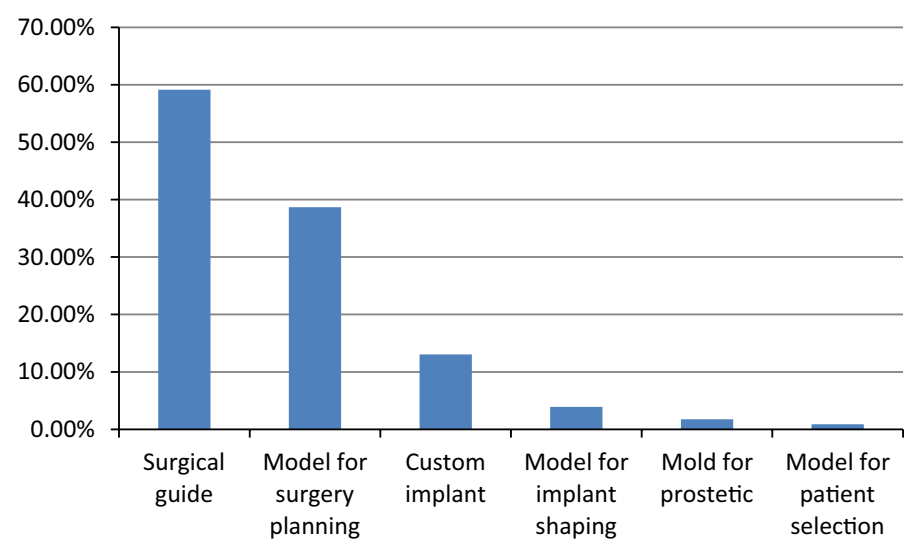

Fig. 3 Overview of the usage of 3D-printing techniques as percentage of total number of papers

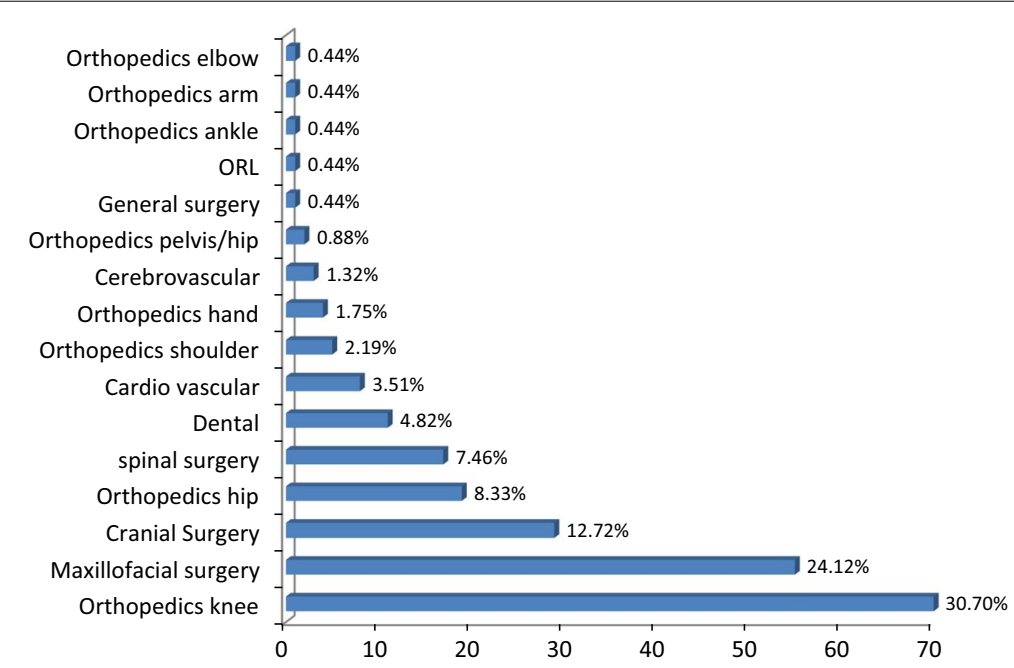

Fig. 4 Overview of papers per specific field

The reports on 3D printing outcomes concern multiple surgical domains. Orthopedics has the largest share, with $45.18 \%$ (Fig. 4): this is made up of knee (30.70 \%), hip (8.33\%), shoulder $(2.19 \%)$, and hand (1.75\%) orthopedics. Maxillofacial surgery also accounts for a large share $(24.12 \%)$. This is followed by cranial surgery and spinal surgery, representing 12.72 and $7.46 \%$ respectively.

More in-depth results are collected in an overview table (Table 1). The data is organized by usage of the technology and discipline. An overview of the number of papers is given in each category. The total of 270 exceeds the total number of papers, as one paper can address multiple usages of 3D printing. The first variable in the table is impact on operation room (OR) time/treatment time. Reductions in operating time are assessed as beneficial. Secondly, the accuracy of the printed part is evaluated. As explained above, radiation exposure is only taken into account when the change in radiation exposure is explicitly mentioned in the paper. Medical outcome and cost are the final regular 
Table 1 Evidence table

\begin{tabular}{|c|c|c|c|c|c|c|c|}
\hline \multirow[t]{2}{*}{ Number of studies } & \multirow{2}{*}{ 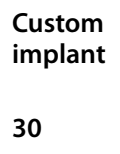 } & \multirow{2}{*}{$\begin{array}{l}\text { Model } \\
\text { for implant } \\
\text { shaping } \\
9\end{array}$} & \multirow{2}{*}{$\begin{array}{l}\text { Model } \\
\text { for patient } \\
\text { selection } \\
2\end{array}$} & \multirow{2}{*}{$\begin{array}{l}\text { Model } \\
\text { for surgery } \\
\text { planning } \\
89\end{array}$} & \multirow{2}{*}{$\begin{array}{l}\text { Mold for } \\
\text { prosthetic } \\
4\end{array}$} & \multirow{2}{*}{$\begin{array}{l}\begin{array}{l}\text { Surgical } \\
\text { guides }\end{array} \\
136\end{array}$} & \multirow{2}{*}{$\begin{array}{l}\text { Total } \\
270\end{array}$} \\
\hline & & & & & & & \\
\hline \multicolumn{8}{|l|}{ OR/treatment time } \\
\hline Not mentioned & 11 & 4 & 2 & 37 & 3 & 68 & 125 \\
\hline Time reduction & $17(4)$ & $5(1)$ & 0 & $48(13)$ & 1 & $53(28)$ & $123(46)$ \\
\hline No time difference & $1(1)$ & 0 & 0 & $3(2)$ & 0 & $8(1)$ & $12(4)$ \\
\hline Time increase & 1 & 0 & 0 & $2(1)$ & 0 & $7(5)$ & $10(6)$ \\
\hline \multicolumn{8}{|l|}{ Accuracy of printed part } \\
\hline Not mentioned & 3 & 1 & 1 & 4 & 0 & 16 & 28 \\
\hline Good/better accuracy & 26 & 8 & 1 & $80(4)$ & 4 & $87(13)$ & $205(17)$ \\
\hline Average accuracy & 1 & 0 & 0 & $6(1)$ & 0 & $23(3)$ & $30(4)$ \\
\hline Bad accuracy & 0 & 0 & 0 & 0 & 0 & $10(6)$ & $10(6)$ \\
\hline \multicolumn{8}{|l|}{ Radiation exposure } \\
\hline Not mentioned & 30 & 7 & 2 & 77 & 4 & 121 & 241 \\
\hline Less radiation & 0 & 0 & 0 & $8(1)$ & 0 & 9 & $17(1)$ \\
\hline equal radiation & 0 & 0 & 0 & 1 & 0 & 2 & 3 \\
\hline Increased radiation & 0 & 2 & 0 & 3 & 0 & 4 & 9 \\
\hline \multicolumn{8}{|l|}{ Clinical outcome } \\
\hline Not mentioned & 1 & 0 & 2 & 10 & 0 & 15 & 28 \\
\hline Improved & $25(2)$ & $9(2)$ & 0 & $73(8)$ & 4 & $85(15)$ & $195(27)$ \\
\hline Equal & 4 & 0 & 0 & $7(1)$ & 0 & $30(7)$ & $41(8)$ \\
\hline Negative impact & 0 & 0 & 0 & 0 & 0 & $7(2)$ & $7(2)$ \\
\hline \multicolumn{8}{|l|}{ Cost } \\
\hline Not mentioned & 16 & 7 & 1 & 52 & 3 & 94 & 173 \\
\hline Cheaper & 0 & 0 & 0 & 4 & 1 & $2(1)$ & $7(1)$ \\
\hline Equally expensive & 0 & 0 & 0 & 1 & 0 & 1 & 2 \\
\hline More expensive & $14(4)$ & $2(2)$ & 1 & $32(21)$ & 0 & $39(19)$ & $88(46)$ \\
\hline \multicolumn{8}{|l|}{ Cost effectiveness } \\
\hline Cost-effective & 1 & 0 & 0 & 8 & 1 & 10 & 19 \\
\hline Neutral & 0 & 0 & 0 & 2 & 0 & 1 & 3 \\
\hline Not cost-effective & 0 & 0 & 0 & 1 & 0 & 6 & 7 \\
\hline
\end{tabular}

(x) Number of studies quantifying the data with numbers/statistics

variables. The last of these, cost effectiveness, is only reported when the authors explicitly mention cost effectiveness. A broader version of the evidence table can be found in Additional file 2.

\section{Custom implants}

Custom implants are used in cranial surgery, dentistry, and maxillofacial surgery [4-32]. According to 17 out of 28 papers, custom implants reduce OR/treatment time. 25 papers mentioned good accuracy of the custom implants and improved medical outcomes. Radiation exposure was not mentioned in these papers. 14 papers mentioned increased costs, but one described an increase in cost effectiveness [4].

The custom implants were mostly made of titanium (10 of 28), polyether ether ketone (PEEK) (10 of 28), epoxide acrylate hydroxyapatite (2 of 28$)$, hydroxyapatite (2 of 28 ), 
polymethyl methacrylate ( 1 of 28 ), polypropylene-polyester ( 1 of 28$)$, and nonspecified acrylic-based resin (4 of 28).

\section{Anatomical models}

Anatomical models can be used for implant shaping in maxillofacial surgery, a topic that was discussed in nine studies [33-41]. Five papers mentioned time reduction as advantage [33, 36, 38-40]. Eight studies concluded that printed models provide good anatomical representations and nine studies mentioned improved surgical outcomes. Two studies mentioned exposure to ionizing radiation $[36,41]$ and two mentioned increased costs $[39,41]$.

Anatomical models are also used in selecting patients for cardiovascular surgery; this was discussed in two studies [42, 43]. None of the papers mentioned time reductions, exposure to ionizing radiation, or medical outcome. One paper found the model to be a good representation of the actual pathology but did not mention the associated costs [42]. Another publication mentioned that costs increased as a result of using an anatomical model [43].

Multiple domains use anatomical models for surgical planning. Our research showed anatomical models being used in cardiovascular surgery, vascular neurosurgery, dental surgery, general surgery, maxillofacial surgery, neurosurgery, cranial/orbital surgery, orthopedics, and spinal surgery $[1-3,9,14,15,35,37,39,43-121]$. Among the 89 studies, 48 (53.93 \%) mentioned reduced operation room time. Two (2.24 \%) studies mentioned increased operation room time and 37 (41.57 \%) did not mention any impact on operation room time. Only 13 of the 48 studies mentioning reduced operation room time and supported this statement with actual numbers or statistics $[3,39,44,72,74$, $78,81,84,99,107,117,119,120]$. In $80(89.89 \%)$ of the publications, the printed part showed good accuracy, although this was only supported numerically in four studies $[3,81,97,106]$. Exposure to ionizing radiation was not mentioned in 77 (86.51\%) of the publications, and eight mentioned decreased exposures [3, 59-61, 74, 79, 101, 107]. Three publications mentioned increased exposure to ionizing radiation [92, 111, 114]. No publication mentioned decreased medical outcomes with the use of anatomical models, while 73 publications mentioned improved medical outcomes. On the cost side, 52 publications did not mention costs, four mentioned decreased costs, and 32 mentioned increased costs. Two-thirds of the studies reporting increased costs supported this claim with numbers or statistics. Eight studies, of which four used the models for maxillofacial surgery, estimated the anatomical models to be cost-effective [44, 58, 67, 74, 79-81, 97].

\section{Molds for prosthetics}

3D-printing techniques can be used to produce molds for making prosthetics, as discussed in three studies $[45,122,123]$. We encountered this approach in cranial surgery, maxillofacial surgery, and ear surgery. In all the studies, the printed parts were accurate and improved the medical outcome. Both cranial studies were discussed in a single paper. One of these studies mentioned reduced OR time as an advantage [45]. The study using 3D-printed molds for ear prosthetics stated that their use reduced costs and was cost-effective [123]. None of these studies mentioned exposure to ionizing radiation. 


\section{Surgical guides}

Surgical guides are the most popular medical application of 3D printing, with mentions in 137 of the 270 papers $(50.74 \%)[10,15,30,31,39,48,59,60,62,70,71,73$, 74, 76, 77, 79-81, 83, 84, 86, 88, 89, 92, 93, 96-98, 106, 108, 111-113, 118, 124-226]. Apart from orthopedics (guides for knee arthroplasties), 3D-printed surgical guides were also used in neurosurgery, dental surgery, spinal surgery, and maxillofacial surgery. 28 of the 53 studies that mentioned reduced operation room time also supported this claim with numbers or statistics $[39,74,81,84,118,131,132,135,136,140,141$, $145,151,152,162,175,177,181,190,194,196,200,207,210-212,219]$. Increased procedural time was seen in seven papers, of which five supported this with numbers or statistics $[62,73,125,143,153,161,225] .88$ studies reported that the guides had good accuracy, while 23 reported average accuracy, and ten mentioned insufficient accuracy. Interestingly, six out of the ten papers reporting insufficient accuracy backed this up with numbers or statistics $[148,165,182,185,191,211]$. Radiation exposure was not mentioned in 123 (89.13\%) studies. Less radiation was mentioned in nine studies, including by six of the 11 spinal surgery studies. Surgical guides improved clinical outcomes in $86(62.31 \%)$ cases, gave similar results in 31 cases, and had a negative impact on clinical outcome in seven studies, all of which were knee orthopedics. The cost associated with the guides was only mentioned in 42 studies, of which 39 stated it to be more expensive and two stated it to be equally expensive. 19 of the 39 studies which indicated that the new technology was more expensive supported this finding with numbers or statistics. Ten studies stated that the guides were cost-effective, while six stated that they were not cost effective. None of these studies backed these claims with numbers.

Considering all applications, the new 3D-printing technology reduced operation room time in $46 \%$ of the studies. $76 \%$ of the studies mentioned that the printed part had good accuracy, and $72 \%$ mentioned improved medical outcomes. On the other hand, $33 \%$ of authors stated that the technology was more expensive.

Table 2 Reported impact of medical 3D printing on operation room time

\begin{tabular}{lllll}
\hline & & Count & Average (in min) & Standard deviation \\
\hline Cranial surgery & Custom implant & 4 & -69.16 & 92.62 \\
Cranial surgery & Custom implant & 3 & -15.81 & 7.74 \\
Maxillofacial surgery & Model for implant shaping & 1 & -42 & \\
Cerebrovascular & Model for surgery planning & 1 & -30 & \\
Maxillofacial surgery & Model for surgery planning & 5 & -5.8 & 78.52 \\
Maxillofacial surgery & Model for surgery planning & 4 & -43.5 & 24.52 \\
Orthopedics hip & Model for surgery planning & 2 & 0.75 & 6.75 \\
Spinal surgery & Model for surgery planning & 2 & -45.5 & 17.5 \\
Maxillofacial surgery & Surgical guide & 6 & -60.33 & 61.85 \\
Orthopedics ankle & Surgical guide & 1 & -12 & \\
Orthopedics hip & Surgical guide & 4 & -0.025 & 5.72 \\
Orthopedics knee & Surgical guide & 20 & -6.73 & 13.68 \\
\hline
\end{tabular}

Italic text outlier correction (outlier defined as study with a highly different outcome compared to the average of the remaining studies within the group) 


\section{Reductions in operation room time}

Operation room time has always been one of the major arguments for medical 3D printing. Of the 227 articles, 42 described the precise impact of using 3D printing technology on OR time. For the majority of applications, 3D printing resulted in time savings. The results are given in Table 2. 3D applications such as surgical guides for maxillofacial surgery, models for spinal and maxillofacial surgical planning, and models for shaping implants used in maxillofacial surgery seem to benefit the most from the technology.

\section{Discussion}

At the time this review was begun, no other analysis of the integration of medical 3D-printing techniques, domain, and use existed. Around mid-2015, Hammad et al. reviewed 93 articles concerning current surgical applications [227]. Both their review and the present one come to similar conclusions. This review is more elaborate, including as it does 227 surgical papers and using a standardized form to evaluate these papers.

One of the main inclusion criteria was the use of 3D-printed materials for in vivo medical purposes. Papers describing 3D models used for medical teaching and testing purposes were therefore not included. Case series of four or more trials were considered, as we believe these reflect the maturity of the technological application for the specific domain. The number of publications meeting our selection criteria is increasing: only two studies were selected from 1999, while there were 70 qualifying studies in 2015, showing the growing interest of the medical sector in 3D-printing technologies. 3D-printed parts have several purposes in the medical setting. While anatomical models made up the biggest share in the early years of medical 3D printing, the growing importance of 3D-printed guides is noticeable. Surgical guides are now the most commonly reported type of 3D-printed application, with $60 \%$ of studies mentioning the use of printed surgical guides.

\section{Anatomical models}

3D-printed anatomical models see broad use in the surgical field. Our review suggests that, in orthopedics, their use has been shown to be beneficial, especially in complex hip replacements, where improved medical outcomes were reported unanimously. Also, studies of cranial (mostly orbital) fractures have reported improved results which have been credited to the use of anatomical models as guides prior to and during surgery, in order to understand the pathology better and to avoid pitfalls. These cranial anatomical models are often also used to shape the implant prior to surgery, resulting in an improved fit of the implant, improved medical outcome, and reduced surgical time. As with the anatomical models used for orthopedic and cranial purposes, our research suggests that spinal and maxillofacial models improve operation planning and clinical outcome, while reducing operation time. Furthermore, anatomical models can reduce the need for fluoroscopy during spinal surgery, reducing exposure to ionizing radiation.

Our research found anatomical models useful for planning vascular procedures such as percutaneous valve implantation, repair of aorta and cranial aneurisms, and surgical planning of complex congenital heart malformations. Furthermore, two cardiovascular studies suggested that the models improve patient selection for endovascular procedures, as compared with standard medical imaging. 
Anatomical models can have direct usage during surgical procedures. During tooth transplant surgery, 3D models of teeth are used to prepare the donor site, improving the procedure's success rates. Furthermore, anatomical models of the mouth are used to make drilling guides for dental implants and to make custom obturators for patients following maxillectomy. The latter reduced the amount of labor-intensive work on the part of both dentists and technicians. Furthermore, maxillofacial models are frequently used to shape implants prior to surgery, further enhancing surgical speed while improving clinical and esthetic outcomes.

Although anatomical models can be used on their own, our study perceived a tendency toward using anatomical models in combination with printed surgical guides. Apart from the previously mentioned benefits, anatomical models can be used for teaching medical students and can improve patient communication and knowledge of the pathology.

\section{Surgical guides}

Our research suggests that surgical guides are well incorporated in orthopedic surgery, spinal surgery, maxillofacial surgery, and dental surgery with more than half of the selected studies of our review mentioning the use of guides. Knee surgeons seem to be most interested in using guides. The uniquely positive results of knee orthopedic papers from 2012 gave way to more neutral results the years after, suggesting the initial excitement was tempered when the technology became more common. More recent studies mention no substantial difference in clinical outcome between patient-specific guides and standard instrumentation for total knee arthroplasty. Increased procedural complexity and less-experienced low-volume surgeons favor the use of surgical guides. Apart from clinical results, patient-specific guides reduce the number of surgical trays needed and slightly reduce OR time. Greater reductions in OR time were when surgeons have become more used to the guided procedure, according to one of the selected papers. Cost-effectiveness remains to be proven, but recent studies mentioning the cost-effectiveness of knee-guides suggest that the technology does not offer enough advantages to cover the additional costs associated with the guides.

Based on our findings, surgical guides seem to reduce operation room time and improve medical outcomes for spinal and cranial surgery. This is due to the simulation on models and the accurate translation of the preliminary surgery by means of guides. More than half of the selected studies reported reduced exposure to ionizing radiation (Additional file 1) due to the decreased need for fluoroscopy. In maxillofacial surgery, 3D-printed models and surgical guides are increasingly used for mandibular reconstructions and orthognathic surgery. The guides are used for the resection of both the mandibular part and the graft, as well as to reconstruct the missing part during oncological mandibular resections and reconstructions. According to the results of our research, spinal surgical guides translate the surgical planning accurately and make the outcomes less dependent on the surgeon's experience. Similar results are seen with the use of guides during dental surgeries. Some authors question the systematic use of dental guides because of the associated higher costs, and suggest that guides be used only in complex cases. Finally, 3D-printed stereotactic fixtures can be used to guide implantation of deep brain stimulation implants with a substantial reduction of surgical time. 
The accuracy of the guide or model and the accurate placement of the guide play important roles in the final clinical outcome or advantage provided by the model. The overlap between accuracy and clinical outcome is therefore unavoidable. The accuracy of guides can vary depending on the manufacturer providing the 3D-printed element and the time between the scan used for the production of the guide and the moment of surgery. Furthermore, surgical experience is needed to detect defective guides. Finally, the use of MRI or CT has an impact on the accuracy of the guide.

\section{Custom implants}

Anatomical models can be used as molds to manufacture prosthetics, as seen in selected cranial and ear surgery studies. Furthermore, patient-specific 3D-printed prosthetic molds have been used in chin augmentation surgery, resulting in both decreased surgical time and an improved esthetic outcome on account of the personal profile match. Finally, our research (Additional file 2) suggests that 3D-printing techniques can successfully be used to directly print the final implant, most commonly in cranial surgery. Cranial custom implants seem to be accurate and to decrease OR time, while being associated with improved clinical outcomes in nearly all the studies considered.

Likewise, 3D-printed trays and fixation plates improve medical outcomes and reducing operation room time for maxillofacial surgery. Moreover, one selected study presented the additional advantage of improved bone formation and angiogenesis with the use of custom implants.

Finally, complete dentures can also be made by rapid prototyping. The results vary, with one study mentioning lower esthetics for 3D-printed dentures and another study mentioning esthetics similar to standard dentures, while highlighting the advantages of face simulation before printing the final prosthetic.

\section{General}

3D-printing techniques are widely used for medical purposes. In the majority of the studies selected here, the medical outcome is improved by the use of 3D-printing. However, we believe that the enthusiasm should be tempered somewhat, as only $14 \%$ of the investigated studies supported this statement with numbers, making this major advantage rather subjective.

Operation time reduction is mentioned in nearly half of the selected studies and backed with numbers in only two-thirds of these cases. In general, most 3D-printing applications seem to reduce the OR time, but wide variances can be seen between the different usages. Some OR time reductions are too small to result in relevant benefits. Although OR time reduction is a major advantage that could contribute to significant financial reduction, the increased time needed for surgical planning is rarely considered. Few studies explicitly mentioned the increased preparation time or discussed whether outsourcing surgical planning is an option. According to two selected studies using surgical guides for knee arthroplasties, surgeons and patients spend more time preparing for surgery than can be reduced during the surgery. Furthermore, these studies suggest that planning might more accurate when performed by the surgeon than when outsourced.

Although the large majority of the selected studies do not mention exposure to ionizing radiation, two-thirds of the studies that do mention radiation report a decrease in 
this ionizing radiation. This can be explained by the high proportion of spinal surgery applications that mentioned decreased exposure to ionizing radiation, as fluoroscopic guidance is a well-known practice in that specific domain. It would be questionable to extrapolate this finding to other domains, as medical 3D printing requires CT scans or MRI. The first of these exposes the patient to a significant amount of ionizing radiation; fluoroscopic guidance, on the other hand, is not that frequently used.

Patients can additionally benefit from technology as anatomical models improve patient understanding of the pathology and procedure. This results in improved patientdoctor communication and greater patient satisfaction. Tactile anatomical models can also assist medical and surgical students to improve their knowledge.

Cost-effectiveness of the new technology is suggested in $7 \%$ of the selected publications, but is nowhere supported by numbers. Other publications question the cost-effectiveness and conclude that the use of 3D printing is not cost effective. Several authors mention that the complexity of cases can justify the additional cost of surgical guides. The growing economic pressure on healthcare makes it increasingly important for researchers to consider the economic sides of new technologies and techniques. Even small analyses made by non economists can be an indication of whether a new technique tends to be cost-effective or not. Fuller cost-effectiveness studies would be needed to evaluate the acceptability of the technology, both for complex cases and for routine cases using 3D printing. Although this was one of the key points of this review, few data on it could be found in the literature.

The cost of 3D-printed parts depends heavily on the manufacturing facility. Cheap desktop 3D-printers allow cheap 3D models and guides, but have less quality approvals and controls than commercial manufacturers, who are required to meet high quality standards. Furthermore, the reported costs of self-printed parts differ from author to author, with few mentioning direct preparation costs (CT, MRI, multiple prints, software, and computer) or the time cost involved in designing the model. The heterogeneity of these printed parts prevents more in-depth analysis. Therefore, we would encourage future research to present the data in a much more transparent and objective way, and to make the first steps into cost-effectiveness calculations.

Although we considered additional articles found in the references of the selected publication, we are aware that some relevant articles might have been missed. We included case series and trials with four or more observations with the assumption that the most integrated practices will have publications stating their specific use. This means that subjects only reported in case reports could have been missed, even if they were well integrated. Surgical publications were considered and analyzed using an evidence table. Not all aspects that might be advantageous for a specific usage can be considered, especially when these advantages are not the direct result of the 3D-printed part. Medical 3D-printing applications used for testing, demonstrations, and training only were not incorporated in this review.

\section{Conclusion}

3D printing is already well integrated in medical practice and the literature. Applications vary from anatomical models (mainly for surgical planning) to surgical guides and implants. The main advantages stated by the authors of the selected papers are reduced 
surgical time, improved medical outcome, and decreased radiation exposure. Unfortunately, the subjective character and lack of evidence supporting majority of these advantages does not allow for conclusive statements. The increased cost of this new technology, and the often limited or unproven advantages, make it questionable whether 3D printing is cost effective for all patients and applications. Several authors have indicated that medical 3D printing has greater advantages when used to handle complex cases and with less experienced surgeons.

\section{Additional files}

Additional file 1. Data overview. List of included articles with extracted data for OR time, accuracy, radiation, ease of use, cost, cost effectiveness and outcome.

Additional file 2. Full evidence table. Extended version of Table 1 with subdivision per medical specialty.

\section{Abbreviations}

AM: additive manufacturing; CAD: computer aided design; CAM: computer Aided manufacturing; CT: computed tomography; MR: magnetic resonance; OR: operation room; 3D: three-dimensional.

\section{Authors' contributions}

PT carried out the main research and wrote the initial article. LA was involved in designing the study, coordinated the research process and improved the final article. JV was involved in designing the study, coordinated the research process and provided valuable information that contributed to this paper. PG was involved in designing the study and improving the manuscript. All authors read and approved the final manuscript.

\section{Author details}

${ }^{1}$ Department of Public Health, Ghent University, De Pintelaan 185, 9000 Ghent, Belgium. ${ }^{2}$ Ghent University Hospital, Ghent University, De Pintelaan 185, 9000 Ghent, Belgium. ${ }^{3}$ Departement of Economics \& Business Administration, Ghent University, Tweekerkenstraat 2,9000 Ghent, Belgium.

\section{Acknowledgements}

Not Applicable.

Competing interests

The authors declare that they have competing interests.

\section{Data availability}

All data generated or analyzed during this study are included in this published article and its Additional files.

\section{Funding}

The study was supported by a research grant from the 'Vlaams Agentschap Ondernemerschap' and other partners in the consortium, Materialise N.V., Mobelife N.V., Melotte N.V. and Layerwise N.V. The funding sources had no access to the data and no role in study design, data collection, analysis, or interpretation of the data. All authors declared not to have nonfinancial interests that may be relevant to the submitted work.

Received: 3 June 2016 Accepted: 9 October 2016

Published online: 21 October 2016

\section{References}

1. Wurm G, Tomancok B, Pogady P, Holl K, Trenkler J. Cerebrovascular stereolithographic biomodeling for aneurysm surgery. J Neurosurg. 2004;100(1):139-45.

2. D'Urso PS, Thompson RG, Atkinson RL, Weidmann MJ, Redmond MJ, Hall Bl, et al. Cerebrovascular biomodelling: a technical note. Surg Neurol. 1999;52(5):490-500.

3. Izatt MT, Thorpe PLPJ, Thompson RG, D'Urso PS, Adam CJ, Earwaker JWS, et al. The use of physical biomodelling in complex spinal surgery. Eur Spine J. 2007;16(9):1507-18.

4. D'Urso PS, Earwaker WJ, Barker TM, Redmond MJ, Thompson RG, Effeney DJ, et al. Custom cranioplasty using stereolithography and acrylic. Br J Plast Surg. 2000;53(3):200-4.

5. Brie J, Chartier T, Chaput C, Delage C, Pradeau B, Caire F, et al. A new custom made bioceramic implant for the repair of large and complex craniofacial bone defects. J Cranio-Maxillofac Surg. 2013;41(5):403-7.

6. Cao DJ, Yu ZY, Chai G, Liu J, Mu XZ. Application of EH compound artificial bone material combined with computerized three-dimensional reconstruction in craniomaxillofacial surgery. J Cranio-Maxillofac Surg. 2010;21(2):440-3.

7. Chrzan R, Urbanik A, Karbowski K, Moskala M, Polak J, Pyrich M. Cranioplasty prosthesis manufacturing based on reverse engineering technology. Med Sci Monit. 2012;18(1):MT1-110. 
8. Gander T, Essig H, Metzler P, Lindhorst D, Dubois L, Rucker M, et al. Patient specific implants (PSI) in reconstruction of orbital floor and wall fractures. J Cranio-Maxillofac Surg. 2015;43(1):126-30.

9. Han SW, Wang ZY, Hu QG, Han W. Combined use of an anterolateral thigh flap and rapid prototype modeling to reconstruct maxillary oncologic resections and midface defects. J Cranio-Maxillofac Surg. 2014;25(4):1147-9.

10. Haq J, Patel N, Weimer K, Matthews NS. Single stage treatment of ankylosis of the temporomandibular joint using patient-specific total joint replacement and virtual surgical planning. Br J Oral Maxillofac Surg. 2014;52(4):350-5.

11. Inokoshi M, Kanazawa M, Minakuchi S. Evaluation of a complete denture trial method applying rapid prototyping. Dent Mater J. 2012;31(1):40-6.

12. Katase H, Kanazawa M, Inokoshi M, Minakuchi S. Face simulation system for complete dentures by applying rapid prototyping. J Prosthet Dent. 2013;109(6):353-60.

13. Lethaus B, Bloebaum M, Essers B, ter Laak MP, Steiner T, Kessler P. Patient-specific implants compared with stored bone grafts for patients with interval cranioplasty. J Cranio-Maxillofac Surg. 2014;25(1):206-9.

14. Lo LJ, Chen YR, Tseng CS, Lee MY. Computer-aided reconstruction of traumatic fronto-orbital osseous defects: aesthetic considerations. Chang Gung Med J. 2004;27(4):283-91.

15. Mazzoni S, Bianchi A, Schiariti G, Badiali G, Marchetti C. Computer-aided design and computer-aided manufacturing cutting guides and customized titanium plates are useful in upper maxilla waferless repositioning. J Oral Maxillofac Surg. 2015;73:701-7.

16. Rotaru H, Stan H, Florian IS, Schumacher R, Park YT, Kim SG, et al. Cranioplasty with custom-made implants: analyzing the cases of 10 patients. J Oral Maxillofac Surg. 2012;70(2):e169-76.

17. Saijo H, Igawa K, Kanno Y, Mori Y, Kondo K, Shimizu K, et al. Maxillofacial reconstruction using custom-made artificial bones fabricated by inkjet printing technology. J Artif Org. 2009;12(3):200-5.

18. Stoor P, Suomalainen A, Lindqvist C, Mesimäki K, Danielsson D, Westermark A, et al. Rapid prototyped patient specific implants for reconstruction of orbital wall defects. J Cranio-Maxillofac Surg. 2014;42(8):1644-9.

19. Zhou LB, Shang HT, He LS, Bo B, Liu GC, Liu YP, et al. Accurate reconstruction of discontinuous mandible using a reverse engineering/computer-aided design/rapid prototyping technique: a preliminary clinical study. J Oral Maxillofac Surg. 2010;68(9):2115-21.

20. Alonso-Rodriguez E, Cebrián JL, Nieto MJ, Del Castillo JL, Hernández-Godoy J, Burgueño M. Polyetheretherketone custom-made implants for craniofacial defects: report of 14 cases and review of the literature. J Cranio-Maxillofac Surg. 2015:43(7):1232-8.

21. Baumann A, Sinko K, Dorner G. Late reconstruction of the orbit with patient-specific implants using computeraided planning and navigation. J Oral Maxillofac Surg. 2015;73(12):S101-6.

22. Gerbino G, Zavattero E, Zenga F, Bianchi FA, Garzino-Demo P, Berrone S. Primary and secondary reconstruction of complex craniofacial defects using polyetheretherketone custom-made implants. J Cranio-Maxillofac Surg. 2015;43(8):1356-63.

23. Lethaus B, Bloebaum M, Koper D, Poort-Ter Laak M, Kessler P. Interval cranioplasty with patient-specific implants and autogenous bone grafts_-success and cost analysis. J Cranio-Maxillofac Surg. 2014;42(8):1948-51.

24. Manrique OJ, Lalezarzadeh F, Dayan E, Shin J, Buchbinder D, Smith M. Craniofacial reconstruction using patient-specific implants polyether ether ketone with computer-assisted planning. J Cranio-Maxillofac Surg. 2015;26(3):663-6.

25. Mao Y, Xu C, XU J, Li H, Liu F, Yu D, et al. The use of customized cages in revision total hip arthroplasty for Paprosky type III acetabular bone defects. Int Orthop. 2015;39(10):2023-30.

26. Ng ZY, Nawaz I. Computer-designed PEEK implants: a peek into the future of cranioplasty? J Craniofac Surg. 2014;25(1):e55-8.

27. Rammos CK, Cayci C, Castro-Garcia JA, Feiz-Erfan I, Lettieri SC. Patient-specific polyetheretherketone implants for repair of craniofacial defects. J Craniofac Surg. 2015;26(3):631-3.

28. Rana M, Chui CHK, Wagner M, Zimmerer R, Rana M, Gellrich NC. Increasing the accuracy of orbital reconstruction with selective laser-melted patient-specific implants combined with intraoperative navigation. J Oral Maxillofac Surg. 2015;73(6):1113-8.

29. Rosenthal G, Ng I, Moscovici S, Lee KK, Lay T, Martin C, et al. Polyetheretherketone implants for the repair of large cranial defects: a 3-center experience. Neurosurgery. 2014;75(5):523-8.

30. Schwarzkopf R, Brodsky M, Garcia GA, Gomoll AH. Surgical and functional outcomes in patients undergoing total knee replacement with patient-specific implants compared with "off-the-shelf" implants. orthopaedic J Sports Med. 2015;3(7).

31. Wilde F, Hanken H, Probst F, Schramm A, Heiland M, Cornelius CP. Multicenter study on the use of patient-specific CAD/CAM reconstruction plates for mandibular reconstruction. Int J Comput Assist Radiol Surg. 2015;10(12):2035-51

32. Zhong S, Huang GJ, Susarla SM, Swanson EW, Huang J, Gordon CR. Quantitative analysis of dual-purpose, patientspecific craniofacial implants for correction of temporal deformity. Neurosurgery. 2015;11:220-9.

33. Keller EE, Baltali E, Liang X, Zhao K, Huebner M, An KN. Temporomandibular custom hemijoint replacement prosthesis: prospective clinical and kinematic study. J Oral Maxillofac Surg. 2012;70(2):276-88.

34. Kozakiewicz M, Szymor P. Comparison of pre-bent titanium mesh versus polyethylene implants in patient specific orbital reconstructions. Head Face Med. 2013;9:32.

35. Azuma M, Yanagawa T, Ishibashi-Kanno N, Uchida F, Ito T, Yamagata K, et al. Mandibular reconstruction using plates prebent to fit rapid prototyping 3-dimensional printing models ameliorates contour deformity. Head Face Med. 2014;10:1.

36. Lim CGT, Campbell DI, Cook N, Erasmus J. A case series of rapid prototyping and intraoperative imaging in orbital reconstruction. Craniomaxillofac Trauma Reconstr. 2015;8(2):105-10

37. Park SW, Choi JW, Koh KS, Oh TS. Mirror-imaged rapid prototype skull model and pre-molded synthetic scaffold to achieve optimal orbital cavity reconstruction. J Oral Maxillofac Surg. 2015;73(8):1540-53.

38. Shengwei $\mathrm{H}$, Zhiyong W, Qingang $\mathrm{H}$, Wei $\mathrm{H}$. Combined use of an anterolateral thigh flap and rapid prototype modeling to reconstruct maxillary oncologic resections and midface defects. J Craniofac Surg. 2014;25(4):1147-9. 
39. Sieira Gil R, Mari Roig A, Arranz Obispo C, Morla A, Marti Pages C, Llopis Perez J. Surgical planning and microvascular reconstruction of the mandible with a fibular flap using computer-aided design, rapid prototype modelling, and precontoured titanium reconstruction plates: a prospective study. Br J Oral Maxillofac Surg. 2015;53(1):49-53.

40. Yamada H, Nakaoka K, Horiuchi T, Kumagai K, Ikawa T, Shigeta Y, et al. Mandibular reconstruction using custommade titanium mesh tray and particulate cancellous bone and marrow harvested from bilateral posterior ilia. J Plast Surg Hand Surg. 2014;48(3):183-90.

41. Yim HW, Anh N, Kim YK. Facial contouring surgery with custom silicone implants based on a 3D prototype model and ct-scan: a preliminary study. Aesthetic Plast Surg. 2015;39(3):418-24.

42. Schievano S, Sebire NJ, Robertson NJ, Taylor AM, Thayyil S. Reconstruction of fetal and infant anatomy using rapid prototyping of post-mortem MR images. Insights Imaging. 2010;1 (4):281-6.

43. Wilasrusmee C, Suvikrom J, Suthakorn J, Lertsithichai P, Sitthiseriprapip K, Proprom N, et al. Three-dimensional aortic aneurysm model and endovascular repair: an educational tool for surgical trainees. Int J Angiol. 2008;17(3):129-33.

44. D'Urso PS, Barker TM, Earwaker WJ, Bruce LJ, Atkinson RL, Lanigan MW, et al. Stereolithographic biomodelling in cranio-maxillofacial surgery: a prospective trial. J Cranio-maxillo-Fac Surg. 1999;27(1):30-7.

45. Muller A, Krishnan KG, Uhl E, Mast G. The application of rapid prototyping techniques in cranial reconstruction and preoperative planning in neurosurgery. J CranioFac Surg. 2003;14(6):899-914.

46. Poukens J, Haex J, Riediger D. The use of rapid prototyping in the preoperative planning of distraction osteogenesis of the cranio-maxillofacial skeleton. Comput Aided Surg. 2003;8(3):146-54

47. Lee SJ. Clinical application of computer-aided rapid prototyping for tooth transplantation. Aust Endod J. 2004;30(1):29-31.

48. D'Urso PS, Williamson OD, Thompson RG. Biomodeling as an aid to spinal instrumentation. Spine. 2005;30(24):2841-5.

49. Ngan EM, Rebeyka IM, Ross DB, Hirji M, Wolfaardt JF, Seelaus R, et al. The rapid prototyping of anatomic models in pulmonary atresia. J Thorac Cardiovasc Surg. 2006;132(2):264-9.

50. Curcio R, Perin GL, Chilvarquer I, Borri ML, Ajzen S. Use of models in surgical predictability of oral rehabilitations. Acta Cirurgica Brasileira. 2007;22(5):387-95.

51. Dai KR, Yan MN, Zhu ZA, Sun YH. Computer-aided custom-made hemipelvic prosthesis used in extensive pelvic lesions. J Arthroplasty. 2007;22(7):981-6.

52. Fan X, Zhou H, Lin M, Fu Y, Li J. Late reconstruction of the complex orbital fractures with computer-aided design and computer-aided manufacturing technique. J Craniofac Surg. 2007;18(3):665-73.

53. Guarino J, Tennyson S, McCain G, Bond L, Shea K, King H. Rapid prototyping technology for surgeries of the pediatric spine and pelvis: benefits analysis. J Pediatr Orthop. 2007;27(8):955-60.

54. Hurson C, Tansey A, O'Donnchadha B, Nicholson P, Rice J, McElwain J. Rapid prototyping in the assessment, classification and preoperative planning of acetabular fractures. Injury. 2007;38(10):1158-62.

55. Mavili ME, Canter HI, Saglam-Aydinatay B, Kamaci S, Kocadereli I. Use of three-dimensional medical modeling methods for precise planning of orthognathic surgery. J Craniofac Surg. 2007;18(4):740-7.

56. Schievano S, Migliavacca F, Coats L, Khambadkone S, Carminati M, Wilson N, et al. Percutaneous pulmonary valve implantation based on rapid prototyping of right ventricular outflow tract and pulmonary trunk from MR data. Radiology. 2007;242(2):490-7.

57. Mizutani J, Matsubara T, Fukuoka M, Tanaka N, Iguchi H, Furuya A, et al. Application of full-scale three-dimensional models in patients with rheumatoid cervical spine. Eur Spine J. 2008;17(5):644-9.

58. Kozakiewicz M, Elgalal M, Loba P, Komunski P, Arkuszewski P, Broniarczyk-Loba A, et al. Clinical application of 3D pre-bent titanium implants for orbital floor fractures. J Cranio-Maxillofac Surg. 2009;37(4):229-34.

59. Lu S, Xu YQ, Lu WW, Ni GX, Li YB, Shi JH, et al. A novel patient-specific navigational template for cervical pedicle screw placement. Spine. 2009:34(26):E959-64.

60. Lu S, Xu YQ, Zhang YZ, Xie L, Guo H, Li DP. A novel computer-assisted drill guide template for placement of C2 laminar screws. Eur Spine J. 2009;18(9):1379-85.

61. Riesenkampff E, Rietdorf U, Wolf I, Schnackenburg B, Ewert P, Huebler M, et al. The practical clinical value of threedimensional models of complex congenitally malformed hearts. J Thorac Cardiovasc Surg. 2009;138(3):571-80.

62. Kunz M, Rudan JF, Xenoyannis GL, Ellis RE. Computer-assisted hip resurfacing using individualized drill templates. J Arthroplasty. 2010;25(4):600-6

63. Mao KY, Wang Y, Xiao SH, Liu ZS, Zhang YG, Zhang XS, et al. Clinical application of computer-designed polystyrene models in complex severe spinal deformities: a pilot study. Eur Spine J. 2010;19(5):797-802.

64. Ping FY, Liu W, Chen F, Xu X, Shi ZJ, Yan FG. Simultaneous correction of bilateral temporomandibular joint ankylosis with mandibular micrognathia using internal distraction osteogenesis and 3-dimensional craniomaxillofacial models. J Oral Maxillofac Surg. 2010;68(3):571-7.

65. Tang W, Guo LJ, Long J, Wang H, Lin YF, Liu L, et al. Individual design and rapid prototyping in reconstruction of orbital wall defects. J Oral Maxillofac Surg. 2010;68(3):562-70.

66. Chai G, Zhang Y, Ma X, Zhu M, Yu Z, Mu X. Reconstruction of fronto-orbital and nasal defects with compound epoxied maleic acrylate/hydroxyapatite implant prefabricated with a computer design program. Ann Plast Surg. 2011;67(5):493-7.

67. Daniel M, Watson J, Hoskison E, Sama A. Frontal sinus models and onlay templates in osteoplastic flap surgery. J Laryngol Otol. 2011;125(1):82-5.

68. Feng F, Wang H, Guan XG, Tian WD, Jing W, Long J, et al. Mirror imaging and preshaped titanium plates in the treatment of unilateral malar and zygomatic arch fractures. Oral Surg Oral Med Oral Pathol Oral Radiol Endodontol. 2011;112(2):188-94.

69. Kim BC, Lee CE, Park W, Kim MK, Zhengguo P, Yu HS, et al. Clinical experiences of digital model surgery and the rapid-prototyped wafer for maxillary orthognathic surgery. Oral Surg Oral Med Oral Pathol Oral Radiol Endod. 2011;111(3):278-85 
70. Kozakiewicz M, Elgalal M, Piotr L, Broniarczyk-Loba A, Stefanczyk L. Treatment with individual orbital wall implants in humans-1-year ophthalmologic evaluation. J Cranio-Maxillofac Surg. 2011;39(1):30-6.

71. Yang JC, Ma XY, Lin J, Wu ZH, Zhang K, Yin QS. Personalised modified osteotomy using computer-aided designrapid prototyping to correct thoracic deformities. Int Orthop. 2011;35(12):1827-32.

72. Zhang SY, Liu XM, Xu YJ, Yang C, Undt G, Chen MJ, et al. Application of Rapid Prototyping for Temporomandibular Joint Reconstruction. J Oral Maxillofac Surg. 2011;69(2):432-8.

73. Zhang YAZ, Lu S, Chen B, Zhao JAM, Liu R, Pei GX. Application of computer-aided design osteotomy template for treatment of cubitus varus deformity in teenagers: a pilot study. J Shoulder Elbow Surg. 2011;20(1):51-6.

74. Zhang YZ, Chen B, Lu S, Yang Y, Zhao JM, Liu R, et al. Preliminary application of computer-assisted patient-specific acetabular navigational template for total hip arthroplasty in adult single development dysplasia of the hip. Int J Med Robot. 2011;7(4):469-74.

75. Gong X, Yu Q. Correction of maxillary deformity in infants with bilateral cleft lip and palate using computerassisted design. Oral Surg Oral Med Oral Pathol Oral Radiol. 2012;114(SUPPL. 5):S74-8.

76. Kawaguchi Y, Nakano M, Yasuda T, Seki S, Hori T, Kimura T. Development of a new technique for pedicle screw and magerl screw insertion using a 3-dimensional image guide. Spine. 2012;37(23):1983-8.

77. Lee SJ, Kim E. Minimizing the extra-oral time in autogeneous tooth transplantation: use of computer-aided rapid prototyping (CARP) as a duplicate model tooth. Restor Dent Endod. 2012;37(3):136-41.

78. Lethaus B, Poort L, Bockmann R, Smeets R, Tolba R, Kessler P. Additive manufacturing for microvascular reconstruction of the mandible in 20 patients. J Cranio-Maxillofac Surg. 2012;40(1):43-6.

79. Lu S, Zhang YZ, Wang Z, Shi JH, Chen YB, Xu XM, et al. Accuracy and efficacy of thoracic pedicle screws in scoliosis with patient-specific drill template. Med Biol Eng Comput. 2012;50(7):751-8.

80. Modabber A, Gerressen M, Stiller MB, Noroozi N, Fuglein A, Holzle F, et al. Computer-assisted mandibular reconstruction with vascularized iliac crest bone graft. Aesthetic Plast Surg. 2012;36(3):653-9.

81. Modabber A, Legros C, Rana M, Gerressen M, Riediger D, Ghassemi A. Evaluation of computer-assisted jaw reconstruction with free vascularized fibular flap compared to conventional surgery: a clinical pilot study. Int I Med Robot. 2012;8(2):215-20.

82. Adolphs N, Liu WC, Keeve E, Hoffmeister B. Craniomaxillofacial surgery planning based on 3D models derived from Cone-Beam CT data. Comput Aided Surg. 2013;18(5-6):101-8.

83. Du H, Tian XX, Li TS, Yang JS, Li KH, Pei GX, et al. Use of patient-specific templates in hip resurfacing arthroplasty: experience from sixteen cases. Int Orthop. 2013;37(5):777-82.

84. Hanasono MM, Skoracki RJ. Computer-assisted design and rapid prototype modeling in microvascular mandible reconstruction. Laryngoscope. 2013;123(3):597-604.

85. Jang JH, Lee SJ, Kim E. Autotransplantation of immature third molars using a computer-aided rapid prototyping model: a report of 4 cases. J Endod. 2013;39(11):1461-6.

86. Li B, Zhang L, Sun H, Yuan JB, Shen SGF, Wang XD. A novel method of computer aided orthognathic surgery using individual CAD/CAM templates: a combination of osteotomy and repositioning guides. Br J Oral Maxillofac Surg. 2013;51(8):E239-44.

87. Li H, Wang L, Mao Y, Wang Y, Dai K, Zhu Z. Revision of complex acetabular defects using cages with the aid of rapid prototyping. J Arthroplasty. 2013;28(10):1770-5.

88. Li J, Li P, Lu HL, Shen LD, Tian WD, Long J, et al. Digital Design and Individually Fabricated Titanium Implants for the Reconstruction of Traumatic Zygomatico-Orbital Defects. J Craniofac Surg. 2013;24(2):363-8.

89. Otsuki B, Takemoto M, Kawanabe K, Awa Y, Akiyama H, Fujibayashi S, et al. Developing a novel custom cutting guide for curved peri-acetabular osteotomy. Int Orthop. 2013;37(6):1033-8.

90. Parchi PD, Ferrari V, Piolanti N, Andreani L, Condino S, Evangelisti G, et al. Computer tomography prototyping and virtual procedure simulation in difficult cases of hip replacement surgery. Surg Technol Int. 2013;23:228-34.

91. Pepper J, Petrou M, Rega F, Rosendahl U, Golesworthy T, Treasure T. Implantation of an individually computerdesigned and manufactured external support for the Marfan aortic root. Multimed Man. 2013;2013:mmt004.

92. Shehab MF, Barakat AA, Abdelghany K, Mostafa Y, Baur DA. A novel design of a computer-generated splint for vertical repositioning of the maxilla after le Fort i osteotomy. Oral Surg Oral Med Oral Pathol Oral Radiol. 2013;115(2):e16-25.

93. Wang J, Liu JF, Liu W, Wang JC, Wang SY, Gui L. Application of computer techniques in repair of oblique facial clefts with outer-table calvarial bone grafts. J Craniofac Surg. 2013;24(3):957-60.

94. Wang WH, Zhu J, Deng JY, Xia B, Xu B. Three-dimensional virtual technology in reconstruction of mandibular defect including condyle using double-barrel vascularized fibula flap. J Cranio-Maxillofac Surg. 2013;41(5):417-22.

95. Won SH, Lee YK, Ha YC, Suh YS, Koo KH. Improving pre-operative planning for complex total hip replacement with a rapid prototype model enabling surgical simulation. Bone Joint J. 2013;95B(11):1458-63.

96. Abdel-Moniem Barakat A, Abou-Elfetouh A, Hakam MM, El-Hawary H, Abdel-Ghany KM. Clinical and radiographic evaluation of a computer-generated guiding device in bilateral sagittal split osteotomies. J Cranio-Maxillofac Surg. 2014;42(5):e195-203.

97. Ayoub N, Ghassemi A, Rana M, Gerressen M, Riediger D, Holzle F, et al. Evaluation of computer-assisted mandibular reconstruction with vascularized iliac crest bone graft compared to conventional surgery: a randomized prospective clinical trial. Trials. 2014;15(1):1.

98. Balanescu B, Franklin R, Ciurea J, Mindruta I, Rasina A, Bobulescu RC, et al. A personalized stereotactic fixture for implantation of depth electrodes in stereoelectroencephalography. Stereotact Funct Neurosurg. 2014;92(2):117-25.

99. de Farias TP, Dias FL, Galvao MS, Boasquevisque E, Pastl AC, Sousa BA. Use of prototyping in preoperative planning for patients with head and neck tumors. Head Neck. 2014;36(12):1773-82.

100. Jiao T, Zhu C, Dong X, Gu X. Rehabilitation of maxillectomy defects with obturator prostheses fabricated using computer-aided design and rapid prototyping: a pilot study. Int J Prosthodont. 2014;27(5):480-6.

101. Lin X, Ai FZ, Yin QS, Xia H, Wu ZH, Ma XY. Application of three-dimensional model in the management of irreducible atlanto-axial dislocation. Acta Orthop Traumatol Turc. 2014;48(3):298-302. 
102. Mashiko T, Otani K, Kawano R, Konno T, Kaneko N, Ito Y, et al. Development of three-dimensional hollow elastic model for cerebral aneurysm clipping simulation enabling rapid and low cost prototyping. World Neurosurg. 2014;83:351-61.

103. Prisman E, Haerle SK, Irish JC, Daly M, Miles B, Chan H. Value of preoperative mandibular plating in reconstruction of the mandible. Head Neck. 2014;36(6):828-33.

104. Silberstein JL, Maddox MM, Dorsey P, Feibus A, Thomas R, Lee BR. Physical models of renal malignancies using standard cross-sectional imaging and 3-dimensional printers: a pilot study. Urology. 2014;84(2):268-72.

105. Treasure T, Takkenberg JJM, Golesworthy T, Rega F, Petrou M, Rosendahl U, et al. Personalised external aortic root support (PEARS) in Marfan syndrome: analysis of 1-9 year outcomes by intention-to-treat in a cohort of the first 30 consecutive patients to receive a novel tissue and valve-conserving procedure, compared with the published results of aortic root replacement. Heart. 2014;100(12):969-75.

106. Wilde F, Winter K, Kletsch K, Lorenz K, Schramm A. Mandible reconstruction using patient-specific pre-bent reconstruction plates: comparison of standard and transfer key methods. Int J Comput Assist Radiol Surg. 2014;10(2):129-40.

107. Yang JC, Ma XY, Xia H, Wu ZH, Ai FZ, Zhang K, et al. Clinical application of computer-aided design-rapid prototyping in C1-C2 operation techniques for complex atlantoaxial instability. J Spinal Disord Tech. 2014;27(4):E143-50.

108. Ciocca L, Marchetti C, Mazzoni S, Baldissara P, Gatto MRA, Cipriani R, et al. Accuracy of fibular sectioning and insertion into a rapid-prototyped bone plate, for mandibular reconstruction using CAD-CAM technology. J CranioMaxillofac Surg. 2015;43(1):28-33.

109. Huang H, Hsieh MF, Zhang G, Ouyang H, Zeng C, Yan B, et al. Improved accuracy of 3D-printed navigational template during complicated tibial plateau fracture surgery. Aust Phys Eng Sci Med. 2015;38:109-17.

110. Wu XB, Wang JQ, Zhao CP, Sun $X$, Shi Y, Zhang ZA, et al. Printed three-dimensional anatomic templates for virtual preoperative planning before reconstruction of old pelvic injuries: initial results. Chin Med J. 2015;128(4):477-82.

111. Bauer AS, Storelli DA, Sibbel SE, McCarroll HR, Lattanza LL. Preoperative computer simulation and patient-specific guides are safe and effective to correct forearm deformity in children. J Pediatr Orthop. 2015.

112. Chen Y, Niu F, Yu B, Liu J, Wang M, Gui L. Three-dimensional preoperative design of distraction osteogenesis for hemifacial microsomia. J Craniofac Surg. 2014;25(1):184-8.

113. Iannotti JP, Weiner S, Rodriguez E, Subhas N, Patterson TE, Jun BJ, et al. Three-dimensional imaging and templating improve glenoid implant positioning. J Bone Joint Surg. 2015;97(8):651-8.

114. Kim HN, Liu XN, Noh KC. Use of a real-size 3D-printed model as a preoperative and intraoperative tool for minimally invasive plating of comminuted midshaft clavicle fractures. J Orthop Surg Res. 2015;10:1.

115. Schmauss D, Haeberle S, Hagl C, Sodian R. Three-dimensional printing in cardiac surgery and interventional cardiology: a single-centre experience. Eur J Cardiothorac Surg. 2014;47(6):1044-52.

116. Tan H, Yang K, Wei P, Zhang G, Dimitriou D, Xu L, et al. A novel preoperative planning technique using a combination of $\mathrm{CT}$ angiography and three-dimensional printing for complex toe-to-hand reconstruction. J Reconstr Microsurg. 2015;31(5):369-77.

117. Weinstock P, Prabhu SP, Flynn K, Orbach DB, Smith E. Optimizing cerebrovascular surgical and endovascular procedures in children via personalized 3D printing. J Neurosurg-Pediatr. 2015;16(5):584-9.

118. Xu H, Zhang C, Shim YH, Li H, Cao D. Combined use of rapid-prototyping model and surgical guide in correction of mandibular asymmetry malformation patients with normal occlusal relationship. J Craniofac Surg 2015;26(2):418-21.

119. Xu J, Li D, Ma RF, Barden B, Ding Y. Application of rapid prototyping pelvic model for patients with DDH to facilitate arthroplasty planning: a pilot study. J Arthroplasty. 2015;30(11):1963-70.

120. Yang M, Li C, Li Y, Zhao Y, Wei X, Zhang G, et al. Application of 3D rapid prototyping technology in posterior corrective surgery for Lenke 1 adolescent idiopathic scoliosis patients. Medicine (United States). 2015;94(8):e582.

121. Zeng C, Xiao J, Wu Z, Huang W. Evaluation of three-dimensional printing for internal fixation of unstable pelvic fracture from minimal invasive para-rectus abdominis approach: a preliminary report. Int J Clin Exp Med. 2015;8(8):13039-44.

122. Li M, Lin X, Xu Y. The application of rapid prototyping technique in chin augmentation. Aesthet Plast Surg. 2010;34(2):172-8

123. Turgut G, Sacak B, Kiran K, Bas L. Use of rapid prototyping in prosthetic auricular restoration. J Craniofac Surg 2009:20(2):321-5.

124. Di Giacomo GAP, Cury PR, de Araujo NS, Sendyk WR, Sendyk CL. Clinical application of stereolithographic surgical guides for implant placement: preliminary results. J Periodontol. 2005;76(4):503-7.

125. Hananouchi T, Saito M, Koyama T, Hagio K, Murase T, Sugano N, et al. Tailor-made surgical guide based on rapid prototyping technique for cup insertion in total hip arthroplasty. Int J Med Robot. 2009;5(2):164-9.

126. Liu XJ, Gui L, Mao C, Peng X, Yu GY. Applying computer techniques in maxillofacial reconstruction using a fibula flap: a messenger and an evaluation method. J Craniofac Surg. 2009;20(2):372-7.

127. Lu S, Xu YQ, Zhang YZ, Li YB, Xie L, Shi JH, et al. A novel computer-assisted drill guide template for lumbar pedicle screw placement: a cadaveric and clinical study. Int J Med Robot. 2009;5(2):184-91.

128. Chen $\mathrm{XJ}$, Yuan JB, Wang $\mathrm{CT}$, Huang $\mathrm{YL}$, Kang L. Modular preoperative planning software for computer-aided oral implantology and the application of a novel stereolithographic template: a pilot study. Clin Implant Dent Relat Res. 2010;12(3):181-93.

129. Konrad PE, Neimat JS, Yu H, Kao CC, Remple MS, D'Haese PF, et al. Customized, miniature rapid-prototype stereotactic frames for use in deep brain stimulator surgery: initial clinical methodology and experience from 263 patients from 2002 to 2008. Stereotact Funct Neurosurg. 2011;89(1):34-41.

130. Morea C, Hayek JE, Oleskovicz C, Dominguez GC, Chilvarquer I. Precise insertion of orthodontic miniscrews with a stereolithographic surgical guide based on cone beam computed tomography data: a pilot study. Int J Oral Maxillofac Implants. 2011;26(4):860-5.

131. Barrack RL, Ruh EL, Williams BM, Ford AD, Foreman K, Nunley RM. Patient specific cutting blocks are currently of no proven value. J Bone Joint Surg-Series B. 2012;94(B(11 SUPPL.A)):95-9. 
132. Boonen B, Schotanus MGM, Kort NP. Preliminary experience with the patient-specific templating total knee arthroplasty. Acta Orthop. 2012;83(4):387-93.

133. Kunz M, Rudan JF, Wood GCA, Ellis RE. Hip resurfacing with individualized drill templates-comparison between anterolateral and posterior approach. Curr Orthop Practice. 2012;23(5):473-5.

134. Ng VY, DeClaire JH, Berend KR, Gulick BC, Lombardi AV Jr. Improved accuracy of alignment with patient-specific positioning guides compared with manual instrumentation in TKA. Clin Orthop Relat Res. 2012;470(1):99-107.

135. Noble JW, Moore CA, Liu N. The value of patient-matched instrumentation in total knee arthroplasty. J Arthroplasty. 2012;27(1):153-5.

136. Nunley RM, Ellison BS, Ruh EL, Williams BM, Foreman $\mathrm{K}$, Ford AD, et al. Are patient-specific cutting blocks costeffective for total knee arthroplasty? Clin Orthop Relat Res. 2012;470(3):889-94.

137. Nunley RM, Ellison BS, Zhu JJ, Ruh EL, Howell SM, Barrack RL. Do patient-specific quides improve coronal alignment in total knee arthroplasty? Clin Orthop Relat Res. 2012;470(3):895-902.

138. Yaffe MA, Patel A, Mc Coy BW, Luo M, Cayo M, Ghate R, et al. Component sizing in total knee arthroplasty: patientspecific guides vs. computer-assisted navigation. Biomedizinische Technik. Biomed Eng. 2012;57(4):277-82.

139. Barke S, Musanhu E, Busch C, Stafford G, Field R. Patient-matched total knee arthroplasty: does it offer any clinical advantages. Acta Orthop Belg. 2013;79(3):307-11.

140. Boonen B, Schotanus MGM, Kerens B, van der Weegen W, van Drumpt RAM, Kort NP. Intra-operative results and radiological outcome of conventional and patient-specific surgery in total knee arthroplasty: a multicentre, randomised controlled trial. Knee Surg Sports Traumatol Arthrosc. 2013;21(10):2206-12.

141. Chareancholvanich K, Narkbunnam R, Pornrattanamaneewong C. A prospective randomised controlled study of patient-specific cutting guides compared with conventional instrumentation in total knee replacement. Bone Joint J. 2013:95(b(3)):354-9.

142. Conteduca F, lorio R, Mazza D, Caperna L, Bolle G, Argento G, et al. Evaluation of the accuracy of a patient-specific instrumentation by navigation. Knee Surg Sports Traumatol Arthrosc. 2013;21(10):2194-9.

143. Hamilton WG, Parks NL, Saxena A. Patient-specific instrumentation does not shorten surgical time: a prospective, randomized trial. J Arthroplasty. 2013;28(8 SUPPL):96-100

144. Issa K, Rifai A, McGrath MS, Callaghan JJ, Wright C, Malkani AL, et al. Reliability of templating with patient-specific instrumentation in total knee arthroplasty. J Knee Surg. 2013;26(6):429-33.

145. Kerens B, Boonen B, Schotanus M, Kort N. Patient-specific guide for revision of medial unicondylar knee arthroplasty to total knee arthroplasty: beneficial first results of a new operating technique performed on 10 patients. Acta Orthop. 2013;84(2):165-9.

146. Liu XZ, Shu DL, Ran W, Guo B, Liao X. Digital surgical templates for managing high-energy zygomaticomaxillary complex injuries associated with orbital volume change: a quantitative assessment. J Oral Maxillofac Surg. 2013;71(10):1712-23.

147. Merc M, Drstvensek I, Vogrin M, Brajlih T, Recnik G. A multi-level rapid prototyping drill guide template reduces the perforation risk of pedicle screw placement in the lumbar and sacral spine. Arch Orthop Trauma Surg. 2013:133(7):893-9.

148. Nam D, Maher PA, Rebolledo BJ, Nawabi DH, McLawhorn AS, Pearle AD. Patient specific cutting guides versus an imageless, computer-assisted surgery system in total knee arthroplasty. Knee. 2013;20(4):263-7.

149. Parratte S, Blanc G, Boussemart T, Ollivier M, Le Corroller T, Argenson JN. Rotation in total knee arthroplasty: no difference between patient-specific and conventional instrumentation. Knee Surgery Sports Traumatol Arthrosc. 2013;21(10):2213-9.

150. Pietsch M, Djahani O, Hochegger M, Plattner F, Hofmann S. Patient-specific total knee arthroplasty: the importance of planning by the surgeon. Knee Surgery Sports Traumatol Arthrosc. 2013;21(10):2220-6

151. Pietsch M, Djahani O, Zweiger C, Plattner F, Radl R, Tschauner C, et al. Custom-fit minimally invasive total knee arthroplasty: effect on blood loss and early clinical outcomes. Knee Surg Sports Traumatol Arthrosc 2013;21(10):2234-40.

152. Pornrattanamaneewong $C$, Chareancholvanich $K$, Narkbunnam R. A prospective randomised controlled study of patient-specific cutting guides compared with conventional instrumentation in total knee replacement. J Bone Joint Surg-Series B. 2013;95(B(3)):354-9.

153. Roh YW, Kim TW, Lee S, Seong SC, Lee MC. Is TKA using patient-specific instruments comparable to conventional TKA? A randomized controlled study of one system knee. Clin Orthop Relat Res. 2013;471(12):3988-95.

154. Schweizer A, Furnstahl P, Nagy L. Three-dimensional correction of distal radius intra-articular malunions using patient-specific drill guides. J Hand Surg. 2013;38(12):2339-47.

155. Stronach BM, Pelt CE, Erickson J, Peters CL. Patient-specific total knee arthroplasty required frequent surgeondirected changes. Clin Orthop Relat Res. 2013;471(1):169-74.

156. Sugawara T, Higashiyama N, Kaneyama S, Takabatake M, Watanabe N, Uchida F, et al. Multistep pedicle screw insertion procedure with patient-specific lamina fit-and-lock templates for the thoracic spine: clinical article. J Neurosurg Spine. 2013;19(2):185-90.

157. Thienpont E, Paternostre F, Pietsch M, Hafez M, Howell S. Total knee arthroplasty with patient-specific instruments improves function and restores limb alignment in patients with extra-articular deformity. Knee. 2013;20(6):407-11

158. Victor J, Premanathan A. Virtual $3 D$ planning and patient specific surgical guides for osteotomies around the knee: a feasibility and proof-of-concept study. Bone Joint J. 2013;95((11 Suppl A)):153-8.

159. Vundelinckx BJ, Bruckers L, De Mulder K, De Schepper J, Van Esbroeck G. Functional and radiographic short-term outcome evaluation of the visionaire system, a patient-matched instrumentation system for total knee arthroplasty. J Arthroplasty. 2013;28(6):964-70.

160. Adolphs N, Liu W, Keeve E, Hoffmeister B. RapidSplint: virtual splint generation for orthognathic surgery - results of a pilot series. Comput Aided Surg. 2014;19(1-3):20-8.

161. Asada S, Mori S, Matsushita T, Nakagawa K, Tsukamoto I, Akagi M. Comparison of MRI- and CT-based patientspecific guides for total knee arthroplasty. Knee. 2014;21(6):1238-43. 
162. Barrett W, Hoeffel D, Dalury D, Mason JB, Murphy J, Himden S. In-vivo alignment comparing patient specific instrumentation with both conventional and computer assisted surgery (cas) instrumentation in total knee arthroplasty. J Arthroplasty. 2014;29(2):343-7.

163. Bell SW, Stoddard J, Bennett C, London NJ. Accuracy and early outcomes in medial unicompartmental knee arthroplasty performed using patient specific instrumentation. Knee. 2014;21:S33-6.

164. Cenni F, Timoncini A, Ensini A, Tamarri S, Belvedere C, D'Angeli V, et al. Three-dimensional implant position and orientation after total knee replacement performed with patient-specific instrumentation systems. J Orthop Res. 2014;32(2):331-7.

165. Chen JY, Yeo SJ, Yew AK, Tay DK, Chia SL, Lo NN, et al. The radiological outcomes of patient-specific instrumentation versus conventional total knee arthroplasty. Knee surgery, sports traumatology, arthroscopy: official journal of the ESSKA. 2014;22(3):630-5.

166. Crane C, Marimuthu K, Chen DB, Harris IA, Wheatley E, MacDessi SJ. Radiographic outcome of limb-based versus knee-based patient specific guides in total knee arthroplasty. Knee. 2014;21(6):1244-9.

167. Daniilidis K, Tibesku CO. A comparison of conventional and patient-specific instruments in total knee arthroplasty. Int Orthop. 2014;38(3):503-8.

168. de Wouters S, Tran Duy K, Docquier PL. Patient-specific instruments for surgical resection of painful tarsal coalition in adolescents. Orthopaedics \& traumatology, surgery \& research: OTSR. 2014;100(4):423-7.

169. Ensini A, Timoncini A, Cenni F, Belvedere C, Fusai F, Leardini A, et al. Intra- and post-operative accuracy assessments of two different patient-specific instrumentation systems for total knee replacement. Knee Surg Sports Traumatol Arthrosc. 2014;22(3):621-9.

170. Franceschi JP, Sbihi A. 3D templating and patient-specific cutting guides (Knee-Plan) in total knee arthroplasty: postoperative CT-based assessment of implant positioning. Orthop Traumatol Surg Res. 2014;100(6):S281-6.

171. Helmy N, Dao Trong ML, Kuhnel SP. Accuracy of patient specific cutting blocks in total knee arthroplasty. BioMed Res Int. 2014;2014:562919.

172. Heyse TJ, Tibesku CO. Improved femoral component rotation in TKA using patient-specific instrumentation. Knee. 2014;21(1):268-71.

173. Holzapfel BM, Pilge H, Prodinger PM, Toepfer A, Mayer-Wagner S, Hutmacher DW, et al. Customised osteotomy guides and endoprosthetic reconstruction for periacetabular tumours. Int Orthop. 2014;38(7):1435-42.

174. Kang SH, Lee JW, Lim SH, Kim YH, Kim MK. Verification of the usability of a navigation method in dental implant surgery: in vitro comparison with the stereolithographic surgical guide template method. J Cranio-Maxillofac Surg. 2014:42(7):1530-5.

175. Kassab S, Pietrzak WS. Patient-specific positioning guides versus manual instrumentation for total knee arthroplasty: an intraoperative comparison. J Surg Orthop Adv. 2014;23(3):140-6.

176. Kotela A, Kotela I. Patient-specific computed tomography based instrumentation in total knee arthroplasty: a prospective randomized controlled study. Int Orthop. 2014;38(10):2099-107.

177. MacDessi SJ, Jang B, Harris IA, Wheatley E, Bryant C, Chen DB. A comparison of alignment using patient specific guides, computer navigation and conventional instrumentation in total knee arthroplasty. Knee. 2014;21 (2):406-9

178. Marimuthu K, Chen DB, Harris IA, Wheatley E, Bryant CJ, MacDessi SJ. A multi-planar CT-based comparative analysis of patient-specific cutting guides with conventional instrumentation in total knee arthroplasty. J Arthroplasty. 2014;29(6):1138-42.

179. Moopanar TR, Amaranath JE, Sorial RM. Component position alignment with patient-specific jigs in total knee arthroplasty. Anz J Surg. 2014;84(9):628-32.

180. Moubarak H, Brilhault J. Contribution of patient-specific cutting guides to lower limb alignment for total knee arthroplasty. Orthop Traumatol-Surg Res. 2014;100(4):S239-42.

181. Renson L, Poilvache P, Van den Wyngaert H. Improved alignment and operating room efficiency with patientspecific instrumentation for TKA. Knee. 2014:21(6):1216-20.

182. Scholes C, Sahni V, Lustig S, Parker DA, Coolican MRJ. Patient-specific instrumentation for total knee arthroplasty does not match the pre-operative plan as assessed by intra-operative computer-assisted navigation. Knee Surg Sports Traumatol Arthrosc. 2014;22(3):660-5.

183. Silva A, Sampaio R, Pinto E. Patient-specific instrumentation improves tibial component rotation in TKA. Knee Surg Sports Traumatol Arthrosc. 2014;22(3):636-42.

184. Small T, Krebs V, Molloy R, Bryan J, Klika AK, Barsoum WK. Comparison of acetabular shell position using patient specific instruments vs. standard surgical instruments: a randomized clinical trial. J Arthroplasty. 2014;29(5):1030-7.

185. Victor J, Dujardin J, Vandenneucker $\mathrm{H}$, Arnout N, Bellemans J. Patient-specific guides do not improve accuracy in total knee arthroplasty: a prospective randomized controlled trial. Clin Orthop Relat Res. 2014;472(1):263-71.

186. Woolson ST, Harris AH, Wagner DW, Giori NJ. Component alignment during total knee arthroplasty with use of standard or custom instrumentation: a randomized clinical trial using computed tomography for postoperative alignment measurement. J Bone Joint Surg Am Vol. 2014;96(5):366-72.

187. Yaffe M, Luo M, Goyal N, Chan P, Patel A, Cayo M, et al. Clinical, functional, and radiographic outcomes following total knee arthroplasty with patient-specific instrumentation, computer-assisted surgery, and manual instrumentation: a short-term follow-up study. Int J Comput Assist Radiol Surg. 2014;9(5):837-44.

188. Abane L, Anract P, Boisgard S, Descamps S, Courpied JP, Hamadouche M. A comparison of patient-specific and conventional instrumentation for total knee arthroplasty: a multicentre randomised controlled trial. Bone Joint J. 2015;97:56-63.

189. Huang Z, Wang XZ, Hou YZ. Novel method of fabricating individual trays for maxillectomy patients by computeraided design and rapid prototyping. J Prosthodont. 2015;24(2):115-20.

190. Leeuwen JA, Grogaard B, Nordsletten L, Rohrl SM. Comparison of planned and achieved implant position in total knee arthroplasty with patient-specific positioning guides. Acta Orthop. 2015;86(2):201-7.

191. Abdel MP, von Roth P, Hommel H, Perka C, Pfitzner T. Intraoperative navigation of patient-specific instrumentation does not predict final implant position. J Arthroplasty. 2015;30(4):564-6. 
192. Boonen B, Schotanus MG, Kerens B, Hulsmans FJ, Tuinebreijer WE, Kort NP. Patient-specific positioning guides for total knee arthroplasty: no significant difference between final component alignment and pre-operative digital plan except for tibial rotation. Knee Surg Sports Traumatol Arthrosc. 2015: 1-9

193. Chinnappa J, Chen DB, Harris IA, MacDessi SJ. Total knee arthroplasty using patient-specific guides: Is there a learning curve? Knee. 2015;22:613-7.

194. Ferrara F, Cipriani A, Magarelli N, Rapisarda S, De Santis V, Burrofato A, et al. Implant positioning in TKA: comparison between conventional and patient-specific instrumentation. Orthopedics. 2015;38(4):e271-80.

195. Frye BM, Najim AA, Adams JB, Berend KR, Lombardi AV Jr. MRI is more accurate than CT for patient-specific total knee arthroplasty. Knee. 2015;22:609-12.

196. Gan Y, Ding J, Xu Y, Hou C. Accuracy and efficacy of osteotomy in total knee arthroplasty with patient-specific navigational template. Int J Clin Exp Med. 2015:8(8):12192-201.

197. Goyal N, Patel AR, Yaffe MA, Luo MY, Stulberg SD. Does implant design influence the accuracy of patient specific instrumentation in total knee arthroplasty? J Arthroplasty. 2015;30(9):1526-30.

198. Hananouchi T. Sagittal gap balancing with the concept of a single radius femoral component in posterior cruciate sacrificing total knee arthroplasty with patient-specific instrumentation. Int Orthop. 2015;39(4):659-65.

199. Heylen S, Van Haver A, Vuylsteke K, Declercq G, Verborgt O. Patient-specific instrument guidance of glenoid component implantation reduces inclination variability in total and reverse shoulder arthroplasty. J Shoulder Elbow Surg. 2015.

200. Hsu AR, Davis WH, Cohen BE, Jones CP, Ellington JK, Anderson RB. Radiographic outcomes of preoperative CT scan-derived patient-specific total ankle arthroplasty. Foot Ankle Int. 2015;36(10):1163-9.

201. Huang D, Chen M, He D, Yang C, Yuan J, Bai G, et al. Preservation of the inferior alveolar neurovascular bundle in the osteotomy of benign lesions of the mandible using a digital template. $\mathrm{Br} J$ Oral Maxillofac Surg. 2015;53(7):637-41.

202. Kaneyama S, Sugawara T, Sumi M. Safe and accurate midcervical pedicle screw insertion procedure with the patient-specific screw guide template system. Spine. 2015;40(6):E341-8.

203. Kang SH, Kim HJ, Park HW, Lee SH. Maxillary cutting guide for executing a simulated osteotomy and removing the bony interference during orthognathic surgery. J Med Devices. 2015;9(4):044505.

204. Kerens B, Schotanus MG, Boonen B, Kort NP. No radiographic difference between patient-specific guiding and conventional Oxford UKA surgery. Knee Surg Sports Traumatol Arthrosc. 2015;23(5):1324-9.

205. Kunz M, Balaketheeswaran S, Ellis RE, Rudan JF. The influence of osteophyte depiction in CT for patient-specific guided hip resurfacing procedures. Int J Comput Assist Radiol Surg. 2015;10(6):717-26.

206. Merc M, Vogrin M, Recnik G, Drstvensek I, Brajlih T, Friedrich T. Error rate of multi-level rapid prototyping trajectories for pedicle screw placement in lumbar and sacral spine. Chinese J Traumatol. 2014:17(5):261-6.

207. Mihalko WM. Patient-specific cutting guides were not better than conventional instrumentation for total knee arthroplasty. J Bone Joint Surgery Am Vol. 2015;97(22):1891.

208. Nam D, Park A, Stambough JB, Johnson SR, Nunley RM, Barrack RL. The Mark Coventry Award: custom cutting guides do not improve total knee arthroplasty clinical outcomes at 2 years followup. Clin Orthop Relat Res. 2015:474:40-6.

209. Nam D, Williams B, Hirsh J, Johnson SR, Nunley RM, Barrack RL. Planned bone resections using an MRI-based custom cutting guide system versus 3-dimensional, weight-bearing images in total knee arthroplasty. J Arthroplasty. 2015;30(4):567-72.

210. Nankivell M, West G, Pourgiezis N. Operative efficiency and accuracy of patient-specific cutting guides in total knee replacement. ANZ J Surg. 2015;85(6):452-5.

211. Pfitzner T, Abdel MP, von Roth P, Perka C, Hommel H. Small improvements in mechanical axis alignment achieved with mri versus ct-based patient-specific instruments in TKA: a randomized clinical trial. Clin Orthop Relat Res. 2014:472(10):2913-22.

212. Rathod PA, Deshmukh AJ, Cushner FD. Reducing blood loss in bilateral total knee arthroplasty with patient-specific instrumentation. Orthop Clin N Am. 2015;46(3):343.

213. Schepers RH, Raghoebar GM, Vissink A, Stenekes MW, Kraeima J, Roodenburg JL, et al. Accuracy of fibula reconstruction using patient-specific CAD/CAM reconstruction plates and dental implants: a new modality for functional reconstruction of mandibular defects. J Cranio-Maxillofac Surg. 2015;43(5):649-57.

214. Schlatterer B, Linares JM, Cazal J, Merloz P, Plaweski S. Posterior tibial slope accuracy with patient-specific cutting guides during total knee arthroplasty: a preliminary study of 50 cases. Orthop Traumatol Surg Res. 2015;101(6 Suppl):S233-40

215. Schotanus MGM, van Haaren EH, Hendrickx RPM, Jansen EJP, Kort NP. Accuracy of CT-based patient-specific guides for total knee arthroplasty in patients with post-traumatic osteoarthritis. Eur J Orthop Surg Traumatol. 2015:25(8):1313-20.

216. Shi L, Liu W, Yin L, Feng S, Xu S, Zhang ZY. Surgical guide assistant mandibular distraction osteogenesis and sagittal split osteotomy in the treatment of hemifacial microsomia. J Craniofac Surg. 2015;26(2):498-500.

217. Subramanya S, Herald J. Reverse shoulder arthroplasty with patient-specific glenoid implant positioning guides. Tech Shoulder Elbow Surg. 2014;15(4):122-9.

218. Throckmorton TW, Vogt W, Wasmaier J, Hurst JM, Frostick S, Sperling JW. Patient-specific targeting guides for glenoid component placement in shoulder arthroplasty: technique and initial clinical experience. Tech Shoulder Elbow Surg. 2014;15(4):103-8.

219. Toto JM, Chang El, Agag R, Devarajan K, Patel SA, Topham NS. Improved operative efficiency of free fibula flap mandible reconstruction with patient-specific, computer-guided preoperative planning. Head Neck. 2015;37(11):1660-4.

220. Trong MLD, Diezi C, Goerres G, Helmy N. Improved positioning of the tibial component in unicompartmental knee arthroplasty with patient-specific cutting blocks. Knee Surg Sports Traumatol Arthrosc. 2015;23(7):1993-8. 
221. Vlachopoulos L, Schweizer A, Graf M, Nagy L, Furnstahl P. Three-dimensional postoperative accuracy of extraarticular forearm osteotomies using CT-scan based patient-specific surgical guides. BMC Musculoskelet Disord. 2015;16:336.

222. Volpi P, Prospero E, Bait C, Cervellin M, Quaglia A, Redaelli A, et al. High accuracy in knee alignment and implant placement in unicompartmental medial knee replacement when using patient-specific instrumentation. Knee Surg Sports Traumatol Arthrosc. 2015;23(5):1292-8.

223. Ye N, Long H, Zhu S, Yang Y, Lai W, Hu J. The accuracy of computer image-guided template for mandibular angle ostectomy. Aesthetic Plast Surg. 2015;39(1):117-23.

224. Ying B, Ye N, Jiang Y, Liu Y, Hu J, Zhu S. Correction of facial asymmetry associated with vertical maxillary excess and mandibular prognathism by combined orthognathic surgery and guiding templates and splints fabricated by rapid prototyping technique. Int J Oral Maxillofac Surg. 2015:44(11):1330-6.

225. Zinser M, Zoeller J. Computer-designed splints for surgical transfer of 3D orthognathic planning. Fac Plast Surg. 2015;31(5):474-90.

226. Demange MK, Von Keudell A, Probst C, Yoshioka H, Gomoll AH. Patient-specific implants for lateral unicompartmental knee arthroplasty. Int Orthop. 2015;39(8):1519-26.

227. Malik HH, Darwood ARJ, Shaunak S, Kulatilake P, El-Hilly AA, Mulki O, et al. Three-dimensional printing in surgery: a review of current surgical applications. J Surg Res. 2015;199(2):512-22.

Submit your next manuscript to BioMed Central and we will help you at every step:

- We accept pre-submission inquiries

- Our selector tool helps you to find the most relevant journal

- We provide round the clock customer support

- Convenient online submission

- Thorough peer review

- Inclusion in PubMed and all major indexing services

- Maximum visibility for your research

Submit your manuscript at www.biomedcentral com/submit 